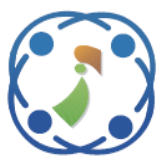

\title{
Enhanced Handoff Decision Making for Application-Aware Environment by Using Blended Approach
}

\author{
Ramandeep Kaur $^{1 *} \quad$ Sumit Mittal $^{1}$ \\ ${ }^{1}$ M.M. Institute of Computer Technology \& Business Management, \\ Maharishi Markandeshwar (Deemed to be University) Mullana, Ambala, Haryana, India \\ * Corresponding author's Email: ramanz2112@yahoo.co.in
}

\begin{abstract}
Seamless integration of the new and existing networks is required to create next generation wireless networks capable of providing wide range of services coupled with uninterrupted connectivity and high speeds offering unprecedented quality of service to users. Smooth and proficient handoff techniques are important to achieve optimal network performance in heterogeneous wireless environments. This paper proposes Multiple Criteria Decision Making (MCDM) techniques of both non-fuzzy (Technique for Order of Performance by Similarity to Ideal Solution (TOPSIS)) and fuzzy (Fuzzy TOPSIS (FTOPSIS)) type for network ranking. The proposed algorithm uses priority ranking to assign weights to six parameters by using Fuzzy Analytic Hierarchy Process (FAHP). Further, TOPSIS and FTOPSIS techniques are compared for various traffic classes and used for network selection in the prevalent network conditions. The results show that contingent on the traffic classes, the FTOPSIS selects the ideal network with diminished ping-pong rate and call blocking probability as compared to TOPSIS while accounting for the uncertain environment.
\end{abstract}

Keywords: Handoff, MCDM, FAHP, TOPSIS, FTOPSIS, Traffic classes, Heterogeneous wireless networks.

\section{Introduction}

With the progression of wireless networks towards the Next Generation Networks (NGN's), not only the user demand for high Quality of Service (QoS) has increased but new challenges in the area of services have also increased. The advent of Heterogeneous Wireless Networks (HWNs) has been emphasizing on integration of various wireless technologies such as $3 \mathrm{G}, 4 \mathrm{G}$, WLAN, WiMAX etc. [1] thereby working arduously on seamless connectivity and overcoming issues like packet loss, delay, ping pong effect etc. It's no more only about the user being mobile all the time, increase in hand held device usage, mobile users addiction to access wide variety of apps (applications- mainly social media or games), more and more easy accessibility of Internet and now the arrival of Internet of Things (IoT), has made researchers to work on 'handoff' in mobility management. Handoff is the process which is initiated by the mobile node ( $\mathrm{MN})$ when its current signal strength drops down below the threshold and the MN needs to connect to another Access Point (AP) for better signal strength[2]. This switching between the AP's or Base Stations (BS's) is dependent not only on signal strength but other handoff parameters like bandwidth, velocity of $\mathrm{MN}$, latency, bit error rate etc. as well. The handoff is carried out in three main phases - handoff initiation, handoff decision making and finally handoff execution [2].

For the network to be Always Best Connected $(\mathrm{ABC})$ and perform an efficient handoff, multi criteria decision making has been preferred over single criteria decision making [3]. Even to maximize the Quality of Service (QoS) experienced by the end user in various types of applications being used, multiple parameters have to be considered thus necessitating the usage of multiple attributes to rank the available candidate networks. Multi Criteria Decision Making (MCDM) is an advance optimization research decision making tool which is 
extensively used for ranking and decision making for an optimal network selection. Various methods have been devised and used in MCDM [3].

Over the years, many researches have been conducted for network selection with the help of MCDM techniques [1,3]. But only few studies considered parameters from all the three categories of handoff parameters (namely terminal-related, network-related and user-related parameters).In this paper, an effective effort has been made to propose a model which uses multiple attributes like signal strength (RSSI), bit error rate, bandwidth, delay, packet loss and line cost to make best network selection. The attributes or parameters chosen range from network related, mobile-related to user-related parameters.

The proposed work has been concentrated on (a) proposing a model for handoff decision making (b) calculating fuzzy normalized weights for the parameters chosen with the blended technique using FAHP for the various traffic classes (c) ranking the available candidate networks using classic MCDM techniques i.e. TOPSIS and FTOPSIS (d) Comparing both the non-fuzzy (TOPSIS) and fuzzy (FTOPSIS) techniques.

The paper has been structured as Section 2 deals with the related work and MCDM classification on the basis of various applications and the study of the MCDM methods used in the proposed model. Section 3 states the contribution of authors. Section 4 gives the proposed framework and its numerical implementation. Section 5 states results along with discussions. The paper conclusion has been given in Section 6.

\section{Related work}

In a heterogeneous wireless environment, whenever the mobile nodes connectivity is going weak and it needs to switch to the suitable available candidate Access Point (AP) to fulfil the requirements of the users (called handoff process)[2], the candidate AP selection turns into a decision making problem as there are multiple options of network alternatives and attributes. In other words, when a mobile node is roaming around in an environment with multiple options of wireless networks and it has to switch to another network (maybe because of weak signal), the mobile node has to select one network from amongst multiple available options. For such a decision making and network selection, MCDM techniques have been the best suitable approach [4].

MCDM denotes the procedure of decision making amongst the available alternatives that have been defined on the basis of multiple available parameters. Authors in [4] have worked on network selection in an LTE and WLAN environment using MCDM methods. Simulations using NS-3 simulator for various parameters and traffic classes have been done. To calculate the weights AHP and FAHP are used along with ranking methods namely TOPSIS, VIKOR, MEW and SAW. The results show that fuzzy method (FAHP) used to calculate weights contributed to decrease in end to end delay and packet loss rate as compared to no fuzzy method (AHP).

In a similar study[5], the authors have embedded three environments WiMAX, WLAN and LTE to study mobile weight, network weight and equal weight. TOPSIS approach has been used to study multiple criteria's and network occupancy for calculating weights. The NS-2 simulation of the proposed multi-criteria based enhanced vertical handover decision algorithm shows improved probabilities of handovers.

\subsection{MCDM methods}

Decision making is an important and tough day to day task. Decision making is required in every sphere of life- science, economics, business, networks etc. From past few years, decision making has been facilitated with Multiple Criteria Decision Making (MCDM) methods. MCDM approaches now form a primary part of decision making theory and analysis. The authors in[6] have defined and classified MCDM methods along with emphasizing their importance in decision making problems especially for public sector enterprises. Going back in history the authors have attributed the historical ties of MCDM to seventeenth century and then to the mid of twentieth century. With the developments in programming and decision making systems it was in 1970's when Thomas L. Saaty defined MCDM techniques like AHP and ANP.

Various researchers have classified MCDM techniques on the basis of numerous classification schemes. The authors of [7] have given classification

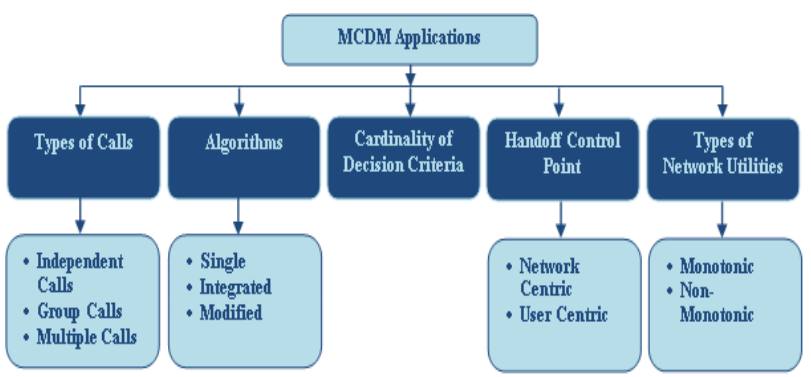

Figure. 1 Application based classification of MCDM methods 
of MCDM methods on the basis of elementary, unique synthesis criterion and outranking criterion. While the authors in [6] have classified them in four basic categories namely selection between alternatives, alternatives rating, alternatives classification and finally identification of alternatives but in this paper, basic classification has been defined on the basis of MCDM methods applications (Fig. 1). Various researchers in multiple areas have developed, defined and applied these approaches. In [7] the authors have given MCDM classification, characteristics, role of weights and other details related to it along with the watershed management criteria as a case study. According to the authors, MCDM is the study of methods and procedures which are incorporated into decision process so as to accommodate multiple and conflicting criteria's. In [3] MCDM has been stated as a division of operation research which is flexible but robust tool for decision making. Also the authors of [7] have defined MCDM methods in three categories namely multi attribute theory, interactive methods and outranking methods.

Apart from the practice of using this optimization tool in areas of science, business, engineering etc., MCDM methods have found a lot of clientele in the field of wireless communication networks. MCDM methods are being widely used for research in handoff decision making techniques and network selection in Heterogeneous Wireless Network (HWN). The authors of [3] have well described the categorization of MCDM application. An MCDM technique can be chosen on the basis of algorithm approach used like single algorithm, integrated algorithm or a modified algorithm. Their study shows that integrated algorithm are used more often as compared to the other two categories.

Further, the authors have defined the MCDM application on the basis of various types of calls such as voice calls, videos, email or web browsing which may further form group calls or multiple calls.

Cardinality of the criteria's selected for the process of handover decision making also form the base of MCDM application [3]. According to the authors, the number of chosen criteria's in a handover process largely affects the decision making process as if the number is too small one might be excluding some important criteria's and on the other hand if the number of chosen criteria's is too large it might reduce the speed of the overall algorithm for network selection.

An MCDM can be chosen on the basis of handoff control point which may be either network-centric or user-centric. In a network-centric handoff scheme, all of the information (from Mobile Node and Network) is gathered by the network entity. But for such a network, overhead for control signals and the processing load increases thereby reducing the network performance for large number of mobile nodes.

A user-centric system uses the mobile node to collect information about the HWN environment for making the handover decision. But to collect the global knowledge of various network parameters like network load conditions is difficult resulting in loss of user synchronization and degradation of the performance.

Another category to decide MCDM application is based on the type of network utility [3]. In an HWN, two types of utilities are defined- monotonic and nonmonotonic. A monotonic utility is defined as monotonic increase or decrease in the measure of satisfaction for an attribute with an increase or decrease in the value of the attribute[8]. For example, signal strength in an HWN can be observed as beneficial as its maximum value is the desired aim but monotonic utilities like delay are regarded as costs because their minimum value is the goal. On the other hand, non-monotonic utilities exist when the user selects access network that has nominal QoS (Quality of Service) for the application instead of selecting the one that offers highest QoS.

\subsubsection{Fuzzy analytic hierarchy process (FAHP)}

Various FAHP methods have been devised and used by researchers. Van Laarhoven and Pedryez, 1983 method is direct extension of Saaty's AHP [9]technique which uses Triangular Fuzzy Numbers (TFN). Its cumbersome calculation requirements make it difficult to use. Buckley's FAHP [9], which is another extension of Saaty's AHP technique, uses the commonly used geometric mean method to develop fuzzy normalized weights and performance scores. FAHP has the advantage of guaranteed unique solution to the reciprocal comparison matrix. This methodical approach is based on integration of two elemental concepts- one, the fuzzy set theory and second, Analytic Hierarchy Process (AHP).The fuzzy approach deals with the uncertainty embedded by ambiguity. Its capacity of handling this vague or uncertain data helps in improving the veracity of the traditional AHP method as it suffered from the inability of expressing the data in crisp values. Authors in[10] have summarized the benefits of using FAHP over the traditional AHP.

In [11] the authors have conducted a study to analyse performance analysis of accuracy of weight calculations in fuzzy comparison matrices. From the wide variety of FAHP methods available to nine methods like Logarithmic Latest Square Method 
(LLSM), LLSM with modified normalization, Fuzzy Extent Analysis (FEA), FEA with modified normalization, Buckley's Geometric Mean Method etc. To conduct the performance analysis, one-way ANOVA method was used. The results are discussed on three parameters- size of matrix, fuzzification and inconsistency. The performance of Buckley is good if the size of matrix is 3 , the performance of FEA methods decreases with increase in fuzzification level.

The authors of[12] used fuzzy AHP with Buckley method to check software quality at architectural level. The maintainability analysis of the software architecture is done with FAHP and compared with other methods like AHP and Chawla method. Results show that FAHP achieves better maintainability as compared to the two other methods.

The handover decision making in [13]is performed using FAHP (for weight calculation), FTOPSIS and fuzzy enhance TOPSIS (for ranking the networks). Four networks have been used for simulation for all the four QoS traffic classes with consideration to six parameters. The MATLAB simulation results helped in determining the best network with less complexity and lower delay.

\subsubsection{Technique for order performance by imilarity to ideal solution (TOPSIS)}

Technique for Order Performance by Similarity to Ideal Solution (TOPSIS) was first given by Hwang and Yoon in 1981 and was later modified by Hwang, Lai and Liu in 1981[14].In this method, the ranking of the alternatives is on the basis of their values which are closer to the ideal solution and farthest from the worst case solution[15].Various studies [1][4][5] have shown TOPSIS to be an ideal method for selection of best network.

In [16] the survey by the authors shapes the research on applications and methodologies of TOPSIS. While defining the TOPSIS procedure, the authors stated that it makes excellent use of attribute information in addition to providing cardinal ranking of the defined attributes. The authors also state that in application of TOPSIS the values of the attributes should be numeric and increasing or decreasing monotonically. Literature regarding various application areas of TOPSIS like supply chain management, health-safety, etc. has been discussed in the paper.

The authors in [1] have found and stated TOPSIS as one of the best MCDM techniques (as compared to SAW, GRA, VIKOR, ELECTRE AND WPM) for network selection scheme. The authors selected seven different parameters for the study and used
Fuzzy rule based input to the MCDM TOPSIS technique. When tested for different HWN, the results show reduction in packet loss, handover latency and the number of handovers.

The basic process can be stated as follows:

1. Obtain the decision matrix (D):

$$
\begin{gathered}
\text { Criteria's } C 1 \ldots \ldots \ldots \text { Cn Alternatives } \\
D_{i j}=\left[\begin{array}{ccc}
d_{i 1} & \cdots & d_{i n} \\
\vdots & & \vdots \\
d_{m 1} & & d_{m n}
\end{array}\right] \begin{array}{c}
A_{1} \\
\vdots \\
A_{m}
\end{array}
\end{gathered}
$$

Where each element of the matrix (d) gives the performance rating for each alternative (A) on the basis of each criteria $(\mathrm{C})$.

2. Normalize the decision matrix(D) :

$$
N_{i j}=\left[\begin{array}{ccc}
n_{i 1} & \cdots & n_{i n} \\
\vdots & & \vdots \\
n_{m 1} & & n_{m n}
\end{array}\right]
$$

Where $\quad n_{i j}=\frac{d_{i j}}{\sqrt{\sum_{i \rightarrow 1}^{m} d_{i j}^{2}}} \quad$ (using $\quad$ Euclidean normalization)

3. Calculate the weighted decision $\operatorname{matrix}\left(V_{i j}\right)$ :

$$
V_{i j}=N_{i j} \times W_{n x n}=\left[\begin{array}{ccc}
V_{i 1} & \cdots & V_{i n} \\
\vdots & & \vdots \\
V_{m 1} & & V_{m n}
\end{array}\right]
$$

Where w gives weights of criteria.

4. Obtain the positive ideal values $(V P)$ \& Negative ideal Values $(V N)$ :

$$
\begin{aligned}
\mathrm{VP} & =\left\{V_{1}^{+}, V_{2}^{+} \ldots \ldots \ldots \ldots \ldots \ldots V_{n}^{+}\right\} \\
\mathrm{VN} & =\left\{V_{1}^{-}, V_{2}^{-} \ldots \ldots \ldots \ldots \ldots \ldots \ldots V_{n}^{-}\right\}
\end{aligned}
$$

5. Calculate $S^{+} \& S^{-}$(Separation Measures) :

$$
\begin{aligned}
& S_{i}^{+}=\sqrt{\left[\sum_{j=1}^{n}\left(V_{i j}-V_{j}^{+}\right)^{2}\right]} \\
& S_{i}^{-}=\sqrt{\left[\sum_{j=1}^{n}\left(V_{i j}+V_{j}^{-}\right)^{2}\right]}
\end{aligned}
$$

6. To calculate relative closeness $\left(C_{i}^{+}\right)$:

$$
C_{i}^{+}=\frac{s_{i}^{-}}{S_{i}^{+}+S_{i}^{-}}, \quad 0 \leq C_{i}^{+} \leq 1
$$

7. For final ranking, the alternative with maximum $\mathrm{CC}_{\mathrm{i}}$ is the highest rank. 


\subsubsection{Fuzzy technique for order performance by similarity to ideal solution (FTOPSIS)}

In an HWN, where multiple networks operate to sustain wide variety of applications used by the user, it is difficult to allocate precise values to different parameters or criteria's. This encourages the use of fuzzy approach not only in assigning values to parameters but also in decision making. Thus, an extension of TOPSIS which is Fuzzy TOPSIS (FTOPSIS) has been used here to solve the problem of decision making in a fuzzy environment.

To prove the development in usage of fuzzy MCDM techniques the authors in [16] have done exhaustive literature survey of different fuzzy models and FTOPSIS method which have been used in decision making. Fuzzy models defined for decision making process like FAHP, FTOPSIS and various extensions of FTOPSIS are stated. The authors have mentioned few important areas of application of FTOPSIS. These include selection of a location, supplier selection problem and finally Turkey's sustainable and renewable energy supply systems.

Using multi-criteria's for a VHO (Vertical Handoff) scheme, the authors in [17] have prepared a two module structure- VHO necessity estimation (VHONE) and the target network selection. Three networks were chosen for the study along with nine parameters. Simulation done using MATLAB and RUNEX for these parameters shows when the handoff is necessary and FTOPSIS helps in ranking the available networks on the basis of QoS for the traffic class being used.

To avoid unnecessary handoffs and improve QoS the authors in [18] have used the hybrid method. For weight calculation FANP has been used and for ranking FTOPSIS has been used. The case scenario designed uses nine wireless networks with eight attributes and the results show that for steadier decisions and good QoS, FTOPSIS is better as compared to TOPSIS, modified GRA and FGRA.

The research studies analysed by authors in[19]for the time period 2009-2018 shows that MCDA (MCD Analysis) methods are being used widely in many practical areas like supply chain management, energy technology, performance evaluation, healthcare and networks etc. MCDA methods like TOPSIS and fuzzy TOPSIS has been chosen for the literature review.

In [20] limitation, issues and comparison of TOPSIS and FTOPSIS has been done on the concepts of truth, reliability and meaning. The authors have emphasized on the issue of reliability of information being used in FTOPSIS and found it to be a challenging task. They have provided a solution to this in fuzzy TOPSIS by Chen. The proposed framework transforms all the fuzzy set information (at step 3) into crisp numbers thereby using fuzzy values in first two steps and crisp values in the other three steps of FTOPSIS by Chen.

The process of FTOPSIS can be summarized as:

1. Create a fuzzy decision matrix

$$
D=\begin{gathered}
\mathrm{C}_{1} \\
A_{1} \\
A_{2} \\
\vdots \\
A_{m}
\end{gathered}\left[\begin{array}{ccc}
d_{i 1} & \ldots & \mathrm{C}_{\mathrm{n}} \\
\vdots & & \vdots \\
d_{m 1} & & d_{m n}
\end{array}\right]
$$

Where $D_{i j}, i=1,2, \ldots \ldots \ldots . m ; j=1,2, \ldots \ldots \ldots n$

$\mathrm{A} 1 \ldots \mathrm{A}_{\mathrm{m}}$ are $\mathrm{m}$ feasible alternatives

$\mathrm{C} 1 \ldots \mathrm{C}_{\mathrm{n}}$ are $\mathrm{n}$ feasible criteria's

2. Normalize the fuzzy decision matrix (D)

$$
\widetilde{N}=\left[\tilde{n}_{i j}\right]_{m x n}
$$

The weighted fuzzy normalized will be:

$$
V_{w}=\left[\begin{array}{ccc}
V_{i 1} & \cdots & V_{i n} \\
\vdots & & \vdots \\
V_{m 1} & & V_{m n}
\end{array}\right] \text { where } \tilde{v}=\tilde{n}_{i j} \times \widetilde{w}_{j}
$$

where $\widetilde{w}_{j}$ are fuzzy weights of criteria's.

3. Compute Fuzzy Positive ideal solution $(\mathrm{FA}+) \&$ Fuzzy Negative Ideal Solution (FA-):

$$
F A^{+}=\left\{\tilde{V}_{1}^{+}, \tilde{V}_{2}^{+} \ldots \ldots \ldots \ldots \ldots \ldots \ldots \tilde{V}_{n}^{+}\right\}
$$

where $\tilde{V}_{j}^{+}=\max \left\{V_{i j 3}\right\}$

$$
F A^{-}=\left\{\tilde{V}_{1}^{-}, \tilde{V}_{2}^{-} \ldots \ldots \ldots \ldots \ldots \ldots \ldots \tilde{V}_{n}^{-}\right\}
$$

where $\tilde{V}_{j}^{-}=\max \left\{V_{i j 1}\right\}$

4. Compute the distance of each attribute from $\mathrm{FA}+(\mathrm{D}+)$ and $\mathrm{FA}^{-}(\mathrm{D}-)$ using:

$$
\frac{d(\tilde{x}, \tilde{y})=}{\sqrt{\frac{1}{3} \sum_{i=1}^{N}\left(l_{i j}-L_{i j}\right)^{2}+\left(m_{i j}-M_{i j}\right)^{2}+\left(v_{i j}-V_{i j}\right)^{2}}}
$$

5. Compute the coefficients of closeness $\left(C C_{\mathrm{i}}\right)$ for each alternative:-

$$
C C_{\mathrm{i}}=\frac{D_{i}^{-}}{D_{i}^{-}+D_{i}^{+}}
$$


6. For final ranking, the alternative with maximum $C C_{\mathrm{i}}$ is the highest rank.

The work presented here can be differentiated from the existing works in the following ways: (1) To maximize the performance of the system, maximum number of handoff parameters i.e. six has been chosen. (2) Maximum number of studies have used AHP for calculating weights of the parameters but here the authors have used FAHP for weight calculation. (3) The authors have proposed the prioritization and selection of parameters on the basis of Experts Opinion and the literature reviewedwhich is a novel idea. (4) It is one of the few studies which have used the combination of FAHP with TOPSIS and FTOPSIS for application aware network selection in a heterogeneous environment.

\section{Our contribution}

Work done by various researchers have established MCDM techniques as efficient tool for decision making which is perfectly suitable for our work encompassing decision making with regard to selection of suitable networks. Flexibility of MCDM techniques to consider multiple attributes for decision making makes them the best option but they are not equipped to deal with the factors like uncertainties in values, measurements, human judgements and unpredictable environment. In order to take care of these shortcomings we apply fuzzy logic along with MCDM.

Thus in our work, both non fuzzy based MCDM method i.e. TOPSIS and fuzzy based method FTOPSIS have been used to support the difference between non fuzzy and fuzzy MCDM methods. For better results these approaches are combined with few other factors:

1. Priority Ranking: Each traffic class behaves differently under different environmental conditions and give different sets of values. Hence depending upon the traffic class and which parameter is more important for that class, ranking is done. This ranking has been attained by conducting survey in two forms: Expert Opinion Survey and Literature Survey.

2. Traffic Classes: The type of application running on the mobile node and its network requirement must be considered while making network selection decision. Thus, in this work, four traffic classes namely voice, video, background and best effort are considered.

3. Main contribution is made by performing decision making for multiple applications (traffic classes) by calculating weights using FAHP and then using TOPSIS and FTOPSIS.
Table 1. Comparative analysis

\begin{tabular}{|c|c|c|c|c|c|c|c|c|c|}
\hline $\begin{array}{l}\dot{Z} \\
\dot{\boldsymbol{B}}\end{array}$ & 总 导 & 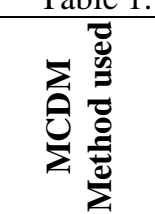 & 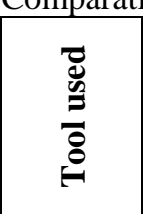 & $\stackrel{\mathscr{c}}{\underline{v}}$ & $\frac{a}{a}$ & 它 & $\mathbf{z}$ & 2 & 焉总 \\
\hline 1 & [1] & $\begin{array}{c}\text { FRB } \\
\text { TOPSIS }\end{array}$ & - & $\checkmark$ & $x$ & $x$ & $\checkmark$ & 7 & $\begin{array}{c}\text { Packet } \\
\text { Loss, } \\
\text { Handoff } \\
\text { Latency }\end{array}$ \\
\hline 2 & [3] & $\begin{array}{c}\text { SAW } \\
\text { GRA } \\
\text { TOPSIS } \\
\text { MULTI- } \\
\text { MOORA }\end{array}$ & $\begin{array}{c}\text { MATLA } \\
\text { B }\end{array}$ & $\checkmark$ & $x$ & $x$ & $x$ & 6 & $\begin{array}{l}\text { Network } \\
\text { Ranking }\end{array}$ \\
\hline 3 & [4] & $\begin{array}{c}\text { FAHP } \\
\text { SAW } \\
\text { MEW } \\
\text { VIKOR } \\
\text { TOPSIS }\end{array}$ & NS3 & $\checkmark$ & $x$ & $x$ & $x$ & 4 & $\begin{array}{c}\text { Packet } \\
\text { Loss } \\
\text { Delay }\end{array}$ \\
\hline 4 & [13] & $\begin{array}{c}\text { FAHP } \\
\text { FTOPSIS }\end{array}$ & - & $\checkmark$ & $x$ & $x$ & $\checkmark$ & 6 & $\begin{array}{l}\text { Network } \\
\text { Ranking }\end{array}$ \\
\hline 5 & [17] & FTOPSIS & $\begin{array}{c}\text { MATLA } \\
\text { B } \\
\text { RUNEX }\end{array}$ & $\checkmark$ & $x$ & $x$ & $\checkmark$ & 9 & $\begin{array}{l}\text { Network } \\
\text { Ranking }\end{array}$ \\
\hline 6 & [18] & $\begin{array}{c}\text { FANP } \\
\text { FTOPSIS }\end{array}$ & - & $x$ & $x$ & $x$ & $\checkmark$ & 8 & $\begin{array}{l}\text { Network } \\
\text { Ranking }\end{array}$ \\
\hline 7 & $\begin{array}{c}\text { Propos } \\
\text { ed } \\
\text { Metho } \\
\text { d }\end{array}$ & $\begin{array}{c}\text { FAHP } \\
\text { TOPSIS } \\
\text { FTOPSIS }\end{array}$ & $\begin{array}{c}\text { MATLA } \\
\text { B }\end{array}$ & $\checkmark$ & $\checkmark$ & $\checkmark$ & $\checkmark$ & 6 & $\begin{array}{l}\text { Network } \\
\text { Ranking }\end{array}$ \\
\hline
\end{tabular}

Traffic Class (TR), Ping Pong Probability (PPP), Call Blocking Probability (CBP), Number of Handovers (NH),Number of Parameters used(PU)

4. To the best of author's knowledge, the comparison of TOPSIS and FTOPSIS till date has been done on the basis of percentage of packet loss and number of handoffs while ignoring the call blocking probability and ping pong rate (Table 1).

5. The optimal network selection result is based on application running and its current status parameters-Network based, user based and mobile based. And results are compared which proves that FTOPSIS is better than TOPSIS.

\section{Proposed enhanced handoff framework using blended approach for next generation networks}

The system model proposed here works on handoff decision phase in which the best available network is chosen (in order to perform handoff) on the basis of given criteria.

Choosing parameters for network selection decision making is a tedious and challenging job. Earlier works like [8] [13] have used common 


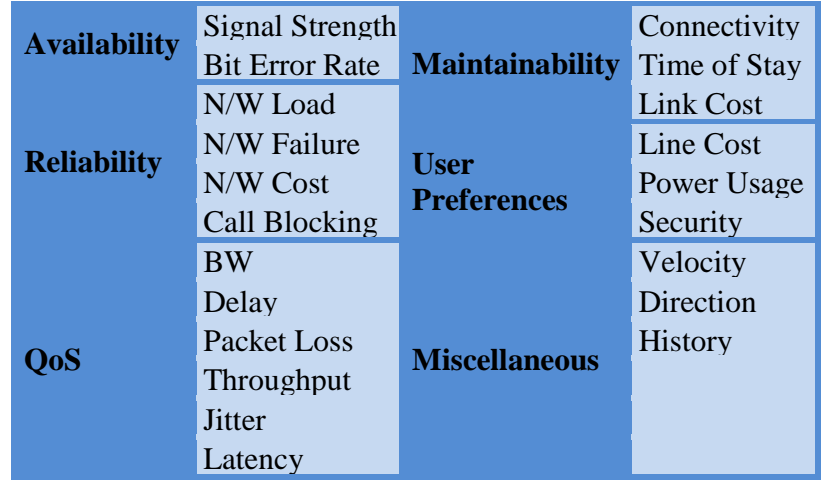

Figure. 2 Parameters provided for expert opinion

parameters like signal strength, delay etc. In this paper, authors have focused on choosing multiple parameters keeping in view the exponentially increasing internet traffic, changing needs of the user and availability of wide variety of network services. Thus to finalize these parameters (from the set of parameters given in Fig. 2), an Expert Analysis along with literature survey has been done. Around ten experts which have their expertise in the field of mobility management, helped in this decision through a questionnaire made by the authors.

The proposed framework (Fig. 3) begins with identification of handoff parameters (Table 1) and then prioritizing these parameters (on the basis of the blended approach of Experts Opinion and literature survey) for various traffic classes namely video, voice, best effort and background. To calculate weights of the parameters with reference to the traffic classes, FAHP has been used.

Finally, TOPSIS and FTOPSIS methods have been used to rank the available networks using the weights given by FAHP.

As stated earlier, the parameters chosen here are from all the three handoff parameters categories as

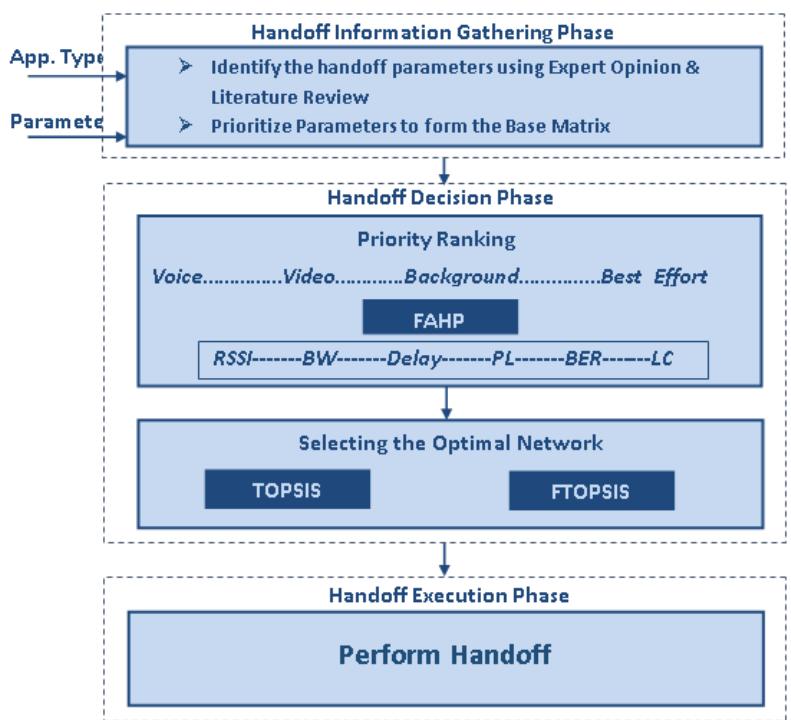

Figure. 3 Proposed framework
Table 2. Parameters chosen for the study

\begin{tabular}{|c|c|c|}
\hline Network & Mobile & User \\
\hline RSSI & Bandwidth & Line Cost \\
\hline BER & Delay & \\
\hline & Packet Loss & \\
\hline
\end{tabular}

shown in Table 2 - network-related parameters (Received Signal Strength Indicator (RSSI), Bit Error Rate (BER)), terminal-related parameters (bandwidth (BW), delay, packet loss (PL)) and user-related parameters (line cost $(\mathrm{LC})$ ).

\section{A. Proposed numerical model}

The optimal network selection or ranking has been done by the authors by using six handoff parameters (Table 2). The final base matrix using blended approach is given in Table 3 .

In the first cycle FAHP (Buckley's Method) [9] has been used to calculate the fuzzy weights of the chosen parameters.

Table 3. Base matrix

\begin{tabular}{|c|c|c|c|c|c|c|}
\hline Parameters $\rightarrow$ & RSSI & BER & BW & Delay & PL & LC \\
Traffic $\downarrow$ & $(\mathrm{P} 1)$ & $(\mathrm{P} 2)$ & $(\mathrm{P} 3)$ & $(\mathrm{P} 4)$ & $(\mathrm{P} 5)$ & $(\mathrm{P} 6)$ \\
\hline Voice & 1 & 3 & 3 & 2 & 4 & 5 \\
\hline Video & 4 & 5 & 1 & 2 & 3 & 6 \\
\hline Best Effort & 1 & 5 & 3 & 2 & 4 & 6 \\
\hline Background & 1 & 5 & 2 & 4 & 3 & 6 \\
\hline
\end{tabular}

Table 4. FAHP Base table for voice class

\begin{tabular}{|c|c|c|c|c|c|c|}
\hline & $\mathrm{P} 1$ & $\mathrm{P} 2$ & P3 & P4 & P5 & P6 \\
\hline $\mathrm{P} 1$ & $(1,1,1)$ & $(2,3,4)$ & $(4,5,6)$ & $(4,5,6)$ & $(6,7,8)$ & $(9,9,9)$ \\
\hline $\mathrm{P} 2$ & $\begin{array}{c}(1 / 4,1 / 3, \\
1 / 2)\end{array}$ & $(1,1,1)$ & $(2,3,4)$ & $(4,5,6)$ & $(4,5,6)$ & $(6,7,8)$ \\
\hline P3 & $\begin{array}{c}(1 / 6,1 / 5, \\
1 / 4)\end{array}$ & $\begin{array}{c}(1 / 4,1 / 3, \\
1 / 2)\end{array}$ & $(1,1,1)$ & $(1,1,1)$ & $(2,3,4)$ & $(4,5,6)$ \\
\hline P4 & $\begin{array}{c}(1 / 6,1 / 5 \\
1 / 4)\end{array}$ & $\begin{array}{c}(1 / 6,1 / 5 \\
1 / 4)\end{array}$ & $(1,1$ & $(1,1,1)$ & $(2,3,4)$ & $(4,5,6)$ \\
\hline P5 & $\begin{array}{c}(1 / 8,1 / 7 \\
1 / 6)\end{array}$ & $\begin{array}{c}(1 / 6,1 / 5 \\
1 / 4)\end{array}$ & $\begin{array}{c}(1 / 4,1 / 3, \\
1 / 2)\end{array}$ & $\begin{array}{c}(1 / 4,1 / 3, \\
1 / 2)\end{array}$ & $(1,1,1)$ & $(2,3,4)$ \\
\hline P6 & $\begin{array}{c}(1 / 9,1 / 9 \\
1 / 9)\end{array}$ & $\begin{array}{c}(1 / 8,1 / 7 \\
1 / 6)\end{array}$ & $\begin{array}{c}(1 / 6,1 / 5, \\
1 / 4)\end{array}$ & $\begin{array}{c}(1 / 6,1 / 5, \\
1 / 4)\end{array}$ & $\begin{array}{l}(1 / 4,1 / \\
3,1 / 2)\end{array}$ & $(1,1,1)$ \\
\hline
\end{tabular}

Table 5. Final normalised fuzzy weight

\begin{tabular}{|c|c|}
\hline Parameter & FAHP Weight \\
\hline RSSI (P1) & 0.4450 \\
\hline Delay(P2) & 0.2626 \\
\hline BW(P3) & 0.1110 \\
\hline BER(P4) & 0.1010 \\
\hline PL(P5) & 0.0523 \\
\hline LC(P6) & 0.0272 \\
\hline
\end{tabular}


Table 6. Base matrix for TOPSIS

\begin{tabular}{|c|c|c|c|c|c|c|}
\hline Parameters $\rightarrow$ & RSSI & Delay & BW & BER & PL & LC \\
\hline Networks $\downarrow$ & & & & & & \\
\hline CN1 & 0.985 & 0.383 & 15.000 & 0.280 & 0.200 & 0.485 \\
\hline CN2 & 0.620 & 0.513 & 20.000 & 0.200 & 0.400 & 0.305 \\
\hline CN3 & 0.708 & 0.715 & 10.000 & 0.220 & 0.500 & 0.870 \\
\hline
\end{tabular}

The base matrix (Table 3) has been used as an input to FAHP model. The weighted matrices obtained from FAHP (Table 5) are then used by TOPSIS and FTOPSIS to rank the three available networks (WiFi (CN1), WiMAX (CN2), LTE-A $(\mathrm{CN} 3))$. Because of the limited scope of representation here in the paper, only Voice class has been shown for the case study (Table 4). The FAHP weights obtained for all the traffic classes are given in Fig. 4.

Once the network parameters have been weighted (Table 5), the second cycle uses TOPSIS and FTOPSIS to rank the available networks. The TOPSIS and FTOPSIS results are as follows:

TOPSIS calculation results have been shown in Table 6 to Table 9. Table 9 gives the final ranking of networks for Voice Class.

FTOPSIS (for Voice Class) results are given in Table 10 to Table 15. FTOPSIS ranking for Voice Class is shown in Table 15. The beneficial and non-
Table 7. TOPSIS normalised matrix with fuzzy weights

\begin{tabular}{|c|c|c|c|c|c|c|}
\hline $\begin{array}{c}\text { Parameters } \rightarrow \\
\text { Networks } \downarrow\end{array}$ & RSSI & Delay & BW & BER & PL & LC \\
\hline CN1 & 0.723 & 0.399 & 0.557 & 0.686 & 0.298 & 0.466 \\
\hline CN2 & 0.455 & 0.535 & 0.743 & 0.490 & 0.596 & 0.293 \\
\hline CN3 & 0.520 & 0.745 & 0.371 & 0.539 & 0.745 & 0.835 \\
\hline Fuzzy Wt. & 0.445 & 0.262 & 0.111 & 0.101 & 0.052 & 0.027 \\
\hline
\end{tabular}

Table 8. TOPSIS with separation measures

\begin{tabular}{|c|c|c|c|c|c|c|c|c|}
\hline Parameters $\rightarrow$ & RSSI & Delay & BW & BER & PL & LC & Sp & Sn \\
\hline Networks $\downarrow$ & & & & & & & \\
\hline CN1 & .322 & .105 & .062 & .069 & .016 & .013 & .123 & .096 \\
\hline CN2 & .203 & .140 & .082 & .050 & .031 & .008 & .039 & .140 \\
\hline CN3 & .231 & .195 & .041 & .054 & .039 & .023 & .107 & .092 \\
\hline Vp & .203 & .105 & .082 & .050 & .016 & .008 & & \\
\hline Vn & .322 & .195 & .041 & .069 & .039 & .023 & \\
\hline
\end{tabular}

Table 9. TOPSIS ranking of the networks

\begin{tabular}{|c|c|c|c|c|c|}
\hline Networks $\downarrow$ & Sp & Sn & Sp+Sn & $\begin{array}{c}\text { Performance } \\
\text { Score }\end{array}$ & Rank \\
\hline CN1 & 0.1227 & 0.0964 & 0.2191 & 0.4400 & 3 \\
\hline CN2 & 0.0388 & 0.1401 & 0.1789 & 0.7831 & 1 \\
\hline CN3 & 0.1074 & 0.0917 & 0.1991 & 0.4606 & 2 \\
\hline
\end{tabular}

beneficial term used in Table 10 represents that whether the criteria mentioned benefits the application or not. If it benefits, it is assigned value 1 else it is assigned 0 .

Table 10. FTOPSIS base matrix

\begin{tabular}{|c|c|c|c|c|c|c|c|c|c|c|c|c|c|c|c|c|c|c|}
\hline & \multirow{2}{*}{\multicolumn{3}{|c|}{\begin{tabular}{|c} 
Non-beneficial \\
RSSI
\end{tabular}}} & \multirow{2}{*}{\multicolumn{3}{|c|}{$\frac{\text { Non-beneficial }}{\text { Delay }}$}} & \multirow{2}{*}{\multicolumn{3}{|c|}{$\frac{\text { Beneficial }}{\text { BW }}$}} & \multicolumn{6}{|c|}{ Non-beneficial Non-beneficial } & \multicolumn{3}{|c|}{ Non-beneficial } \\
\hline & & & & & & & & & & \multicolumn{3}{|c|}{$\frac{\text { Non-beneficial }}{\text { BER }}$} & \multicolumn{3}{|c|}{ PL } & \multicolumn{3}{|c|}{ LC } \\
\hline CN1 & 1 & 2 & 3 & 3 & 4 & 5 & 3 & 4 & 5 & 2 & 3 & 4 & 3 & 4 & 5 & 3 & 4 & 5 \\
\hline CN2 & 2 & 3 & 4 & 1 & 2 & 3 & 5 & 6 & 7 & 3 & 4 & 5 & 4 & 5 & 6 & 5 & 6 & 7 \\
\hline \multirow[t]{2}{*}{ CN3 } & 5 & 6 & 7 & 2 & 3 & 4 & 1 & 2 & 3 & 1 & 2 & 3 & 1 & 2 & 3 & 1 & 1 & 2 \\
\hline & \multicolumn{2}{|c|}{$\operatorname{Max}(\mathrm{c})$} & 7 & \multicolumn{3}{|c|}{$\operatorname{Min}(a)$} & \multicolumn{3}{|c|}{$\operatorname{Max}(\mathrm{c})$} & \multicolumn{3}{|c|}{ Min (a) } & \multicolumn{3}{|c|}{$\operatorname{Min}(a)$} & \multicolumn{3}{|c|}{$\operatorname{Min}(\mathrm{a})$} \\
\hline
\end{tabular}

Table 11. FTOPSIS normalised fuzzy decision matrix (FDM) for voice class

\begin{tabular}{|l|l|l|l|l|l|l|l|l|l|l|l|l|l|l|l|l|l|l|l|}
\hline FAHP Wt. & 0.324 & 0.451 & 0.617 & 0.178 & 0.260 & 0.381 & 0.078 & 0.110 & 0.159 & 0.073 & 0.101 & 0.141 & 0.035 & 0.051 & 0.078 & 0.020 & 0.027 & 0.038 \\
\hline
\end{tabular}

\begin{tabular}{|c|c|c|c|c|c|c|}
\hline & RSSI & Delay & BW & BER & PL & $\mathbf{L C}$ \\
\hline $\mathbf{N 1}$ & \begin{tabular}{l|l|l|}
43 & 0.286 & 0.429 \\
\end{tabular} & \begin{tabular}{|l|l|l|l|}
0.200 & 0.250 & 0.33 \\
\end{tabular} & \begin{tabular}{l|l|l}
429 & 0.571 & 0.7
\end{tabular} & \begin{tabular}{|l|l|}
250 & 0.333 \\
\end{tabular} & 0.250 & \begin{tabular}{|l|l|l|}
00 & 0.250 & 0.333 \\
\end{tabular} \\
\hline & 0 & & & at & 0 & $43|0.167| 0.200$ \\
\hline CN3 & \begin{tabular}{|l|l|l|}
0.714 & 0.857 & 1.000 \\
\end{tabular} & \begin{tabular}{|l|l|l|}
0.250 & 0.333 & 0.50 \\
\end{tabular} & \begin{tabular}{|l|l|l|}
0.143 & 0.286 & 0.429 \\
\end{tabular} & \begin{tabular}{|l|l|l|l|}
0.333 & 0.500 & 1.000 \\
\end{tabular} & \begin{tabular}{|l|l|l|l|l|l|l|l|l|l|l|l|l|} 
& 0.333 & 0.500 & 1.000 \\
\end{tabular} & \begin{tabular}{|l|l|l|}
0.500 & 1.000 & 1.000 \\
\end{tabular} \\
\hline
\end{tabular}

Table 12. FTOPSIS weighted normalised fuzzy decision matrix for voice class

\begin{tabular}{|l|l|l|l|l|l|l|l|l|l|l|l|l|l|l|l|l|l|l|}
\hline FAHP Wt. & 0.324 & 0.451 & 0.617 & 0.178 & 0.260 & 0.381 & 0.078 & 0.110 & 0.159 & 0.073 & 0.101 & 0.141 & 0.035 & 0.051 & 0.078 & 0.020 & 0.027 & 0.038 \\
\hline & \multicolumn{3}{|c|}{ RSSI } & \multicolumn{3}{|c|}{ Delay } & \multicolumn{3}{|c|}{ BW } & \multicolumn{3}{|c|}{ BER } & \multicolumn{3}{|c|}{ PL } & LC \\
\hline CN1 & 0.046 & 0.129 & 0.264 & 0.036 & 0.065 & 0.127 & 0.033 & 0.063 & 0.113 & 0.018 & 0.034 & 0.071 & 0.007 & 0.013 & 0.026 & 0.004 & 0.007 & 0.013 \\
\hline CN2 & 0.092 & 0.193 & 0.353 & 0.059 & 0.130 & 0.381 & 0.056 & 0.094 & 0.159 & 0.015 & 0.025 & 0.047 & 0.006 & 0.010 & 0.019 & 0.003 & 0.004 & 0.008 \\
\hline CN3 & 0.231 & 0.386 & 0.617 & 0.045 & 0.087 & 0.191 & 0.011 & 0.031 & 0.068 & 0.024 & 0.051 & 0.141 & 0.012 & 0.025 & 0.078 & 0.010 & 0.027 & 0.038 \\
\hline
\end{tabular}

Table 13. FPIS (fuzzy positive) \& FNIS (fuzzy negative) ideal solution matrix for voice class

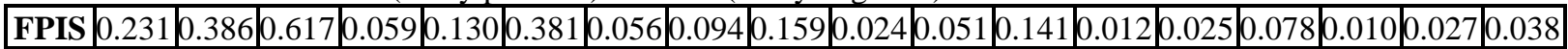
\begin{tabular}{|l|l|l|l|l|l|l|l|l|l|l|l|l|l|l|l|l|l|l|l|l|l|}
\hline FNIS & 0.046 & 0.129 & 0.264 & 0.036 & 0.065 & 0.127 & 0.011 & 0.031 & 0.068 & 0.015 & 0.025 & 0.047 & 0.006 & 0.010 & 0.019 & 0.003 & 0.004 & 0.008 \\
\hline
\end{tabular} 
Table 14. Distance calculation ( $\mathrm{Di} * \& \mathrm{Di}-$ ) matrix for voice class

\begin{tabular}{|c|c|c|c|c|c|c|c|c|c|c|c|c|c|c|c|c|c|}
\hline \multirow{4}{*}{$\sum_{x}^{+}$} & & RSSI & BER & BW & DELAY & PL & LC & Di* & \multirow{4}{*}{$\sum_{\leq 1}^{2}$} & & RSSI & BER & BW & DELAY & PL & LC & Di- \\
\hline & N1 & 0.274 & 0.152 & 0.034 & 0.042 & 0.031 & 0.019 & 0.552 & & N1 & 0.000 & 0.000 & 0.000 & 0.000 & 0.013 & 0.022 & 0.035 \\
\hline & $\mathrm{N} 2$ & 0.205 & 0.000 & 0.000 & 0.057 & 0.035 & 0.022 & 0.319 & & N2 & 0.068 & 0.065 & 0.065 & 0.152 & 0.154 & 0.153 & 0.657 \\
\hline & $\mathbf{N 3}$ & 0.000 & 0.113 & 0.069 & 0.000 & 0.000 & 0.000 & 0.182 & & N3 & 0.274 & 0.252 & 0.204 & 0.039 & 0.039 & 0.037 & 0.845 \\
\hline
\end{tabular}

Table 15. FTOPSIS ranking for voice class

\begin{tabular}{|c|c|c|c|c|}
\hline & Di* $^{*}$ & Di- & Cci & Rank \\
\hline CN1 & 0.5524 & 0.0351 & 0.0597 & 3 \\
\hline CN2 & 0.3192 & 0.6567 & 0.6729 & 2 \\
\hline CN3 & 0.1819 & 0.8446 & 0.8228 & 1 \\
\hline
\end{tabular}

\section{Results and discussions}

The final results for all the traffic classes using TOPSIS and FTOPSIS with FAHP weights are demonstrated in this section.

Fig. 4 gives the parametric-weight representation for various traffic classes using FAHP.

The representation clearly shows the importance of parameters with higher values in various traffic classes. For example, for a voice class, signal strength has to be strong so as the user gets clear voice data and there is no loss of data.

Similarly for a video traffic class, higher bandwidth is required so as the user is able to download the videos speedily and without any data loss.
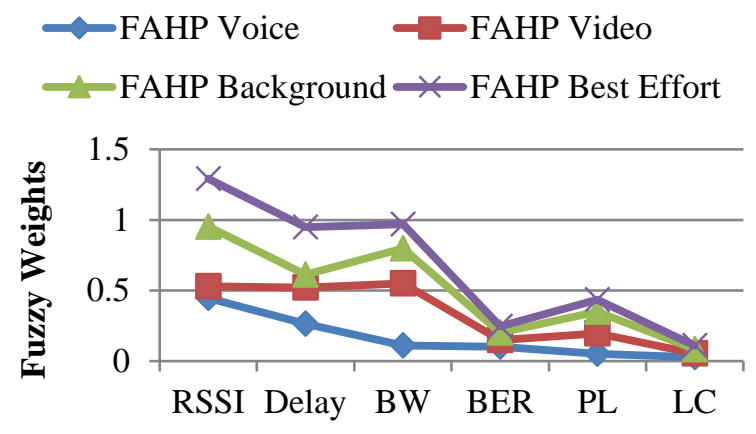

Figure. 4 FAHP results for various traffic classes

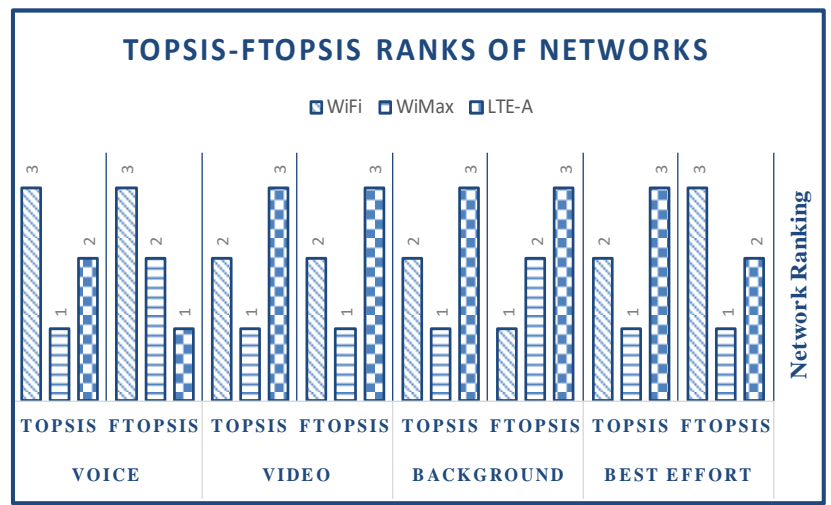

Figure. 5 TOPSIS and FTOPSIS comparison for various networks and four traffic classes
Fig.5 gives the final comparison of the two ranking methods for various networks under study and all the traffic classes. The handoff decision will be taken on the basis of these ranks. It can be seen that there is some difference in the ranking by the two methods. This can be related to the techniques used as one method (TOPSIS) is a non-fuzzy method whereas the other method (FTOPSIS) used is based on fuzzy technique. TOPSIS is a suitable technique for an application where only precise input values can be used. In a HWN, to achieve ideal or exact values of parameters is not possible. A wireless network will always have vague and inaccurate values of the parameters. In such an environment, the proposed method suggests to choose FTOPSIS as a ranking method.

In this paper, parameters have been chosen on the basis of Priority Ranking and concerned weights have been calculated using FAHP. Next, two models FAHP (with Ranking) with TOPSIS (Model-I) and FAHP (with Ranking) with FTOPSIS (Model-II) have been proposed. Results can be concluded as:

i. Ping-Pong Probability: Model-II shows less ping-pong probability as compared to Model-I which means that number of unnecessary

$\square$ Voice Background Best Effort $\square$ Video

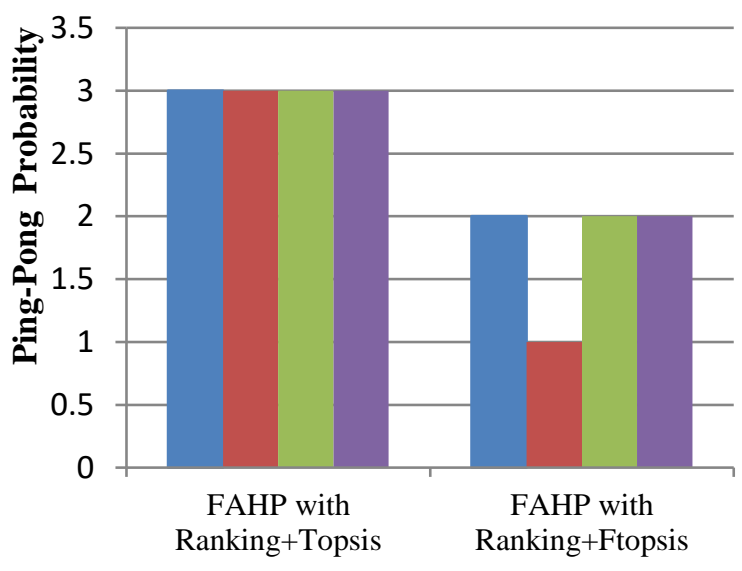

Figure. 6 Ping-pong probability for model - I and model-II 

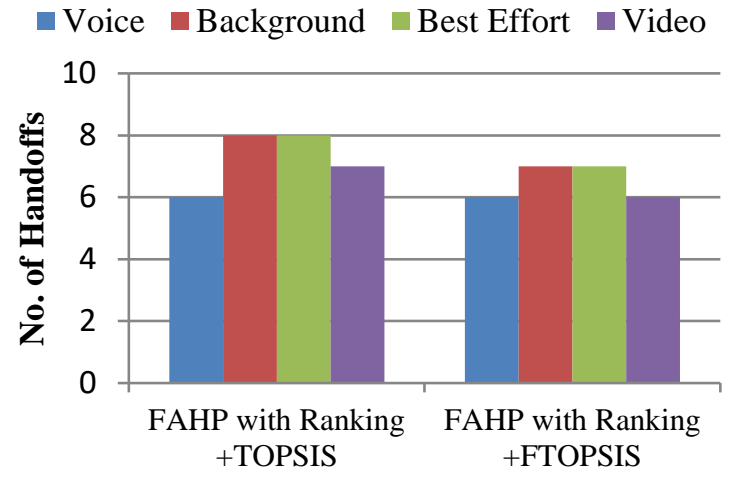

Figure. 7 Number of handoffs for model - I and model-II

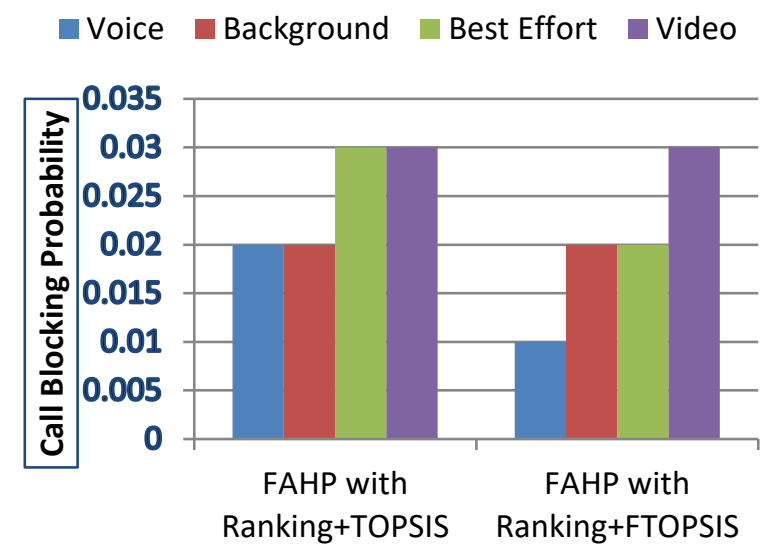

Figure. 8 Call blocking probability for model - I and model-II

handoffs is more in Model-I (Fig. 6).

ii. Number of Handoffs: Both the models are close on number of handoffs. Background, best effort and video show comparatively lesser number of handoffs in Model-II (Fig. 7).

iii. Call Blocking Probability: Model-II has less call blocking probability as compared to Model-1 in case of best effort and voice (Fig. 8).

\section{Conclusion}

For Quality of Service (QoS) in a Heterogeneous Wireless Networks (HWN), seamless connectivity has to be maintained for various applications. Implementation of the proposed method enables the achievement of enhanced performance of the network as the handoff can be done selectively according to the ranking of the networks. Also, results show better performance of Fuzzy based approach (FTOPSIS) over non-fuzzy (TOPSIS) approach like less ping-pong effect, low number of handoffs and low call blocking probability.

The number of parameters to be compared has been considerably increased, the throughput of the application-aware environment will improve remarkably. The application of the fuzzy based weights (using FAHP) helps in achieving precise handoff decision.

Although researchers have shown various Multi Criteria Decision Making techniques to be suitable for ranking of networks, but still limitations like rank reversal exist. In future, better ranking methods and simulating techniques can be used for research by integrating these techniques with predictive analytics.

\section{Conflicts of Interest}

The authors declare no conflict of interest.

\section{Author Contributions}

Conceptualization, Sumit Mittal and Ramandeep Kaur; methodology, Ramandeep Kaur; software, Ramandeep Kaur; validation, Ramandeep Kaur; data curation, Ramandeep Kaur; writing - original draft preparation, Ramandeep Kaur; writing - review and editing, Sumit Mittal and Ramandeep Kaur; visualization, Sumit Mittal and Ramandeep Kaur; supervision, Sumit Mittal.

\section{References}

[1] M. Khan, A. Ahmad, S. Khalid, S. H. Ahmed, S. Jabbar, and J. Ahmad, "Fuzzy based multicriteria vertical handover decision modeling in heterogeneous wireless networks", Multimedia Tools Applications, Springer, Vol. 76, No. 23, pp. 24649-24674, 2017.

[2] R. Kaur and S. Mittal, "SINR and Fuzzy Approach based Enhanced Handoff Decision Making Algorithm", SSRN Electronic Journal, 2020.

[3] E. Obayiuwana and O. E. Falowo, "Network selection in heterogeneous wireless networks using multi-criteria decision-making algorithms: a review", Wireless Networks, Vol. 23, No. 8, pp. 2617-2649, 2017.

[4] M. Drissi, M. Oumsis, and D. Aboutajdine, "A Multi-Criteria Decision Framework for network selection over LTE and WLAN", Engineering Applications of Artificial Intelligence, Vol. 66, No. February, pp. 113-127, 2017.

[5] R. M. Abdullah, A. Z. Abualkishik, and A. A. Alwan, "Improved handover decision algorithm using multiple criteria", Procedia Computer Science, Vol. 141, pp. 32-39, 2018.

[6] H. M. Arslan, Current Classification of Multi Criteria Decision Analysis Methods And Public Sector Implementations, No. December. 2017. 
[7] B. Hassan, N. Kamal, Z. Moniruzzaman, A. S. Zulkifli, S., \& Yusop, SPRINGER BRIEFS IN WATER SCIENCE AND TECHNOLOGY Weighting Methods and their Effects on MultiCriteria Decision Making Model Outcomes in Water Resources Management. 2015.

[8] L. Wang and G.-S. G. S. Kuo, "Mathematical Modeling for Network Selection in Heterogeneous Wireless Networks - A Tutorial", IEEE Communications Surveys \& Tutorials, Vol. 15, No. 1, pp. 271-292, 2013.

[9] T. Demirel, N. Ç. Demirel, and C. Kahraman, "Fuzzy analytic hierarchy process and its application", In Springer Optimization and Its Applications, Vol. 16, pp. 53-83, 2008.

[10] R. Kaur and S. Mittal, "Multi Criteria based Handoff using FAHP and Fuzzy Inference System”, In: Proc. of 2019 International Conf. on Data Science Communication, IconDSC 2019, pp. 1-5, 2019.

[11] F. Ahmed and K. Kilic, "Fuzzy Analytic Hierarchy Process: A performance analysis of various algorithms", Fuzzy Sets Systems, Vol. 362, No. 27, pp. 110-128, 2019.

[12] U. Dayanandan and V. Kalimuthu, "A fuzzy analytical hierarchy process (FAHP) based software quality assessment model: Maintainability analysis", International Journal of Intelligent Engineering Systems, Vol. 11, No. 4, pp. 88-96, 2018.

[13] I. Chattate, M. El Khaili, and J. Bakkoury, "A new fuzzy-topsis based algorithm for enhancing decision making in a heterogeneous network", Journal of Communications, Vol. 14, No. 3, pp. 194-201, 2019.

[14] C. L. Hwang, Y. J. Lai, and T. Y. Liu, "A new approach for multiple objective decision making", Computers and Operations Research, Vol. 20, No. 8, pp. 889-899, 1993.

[15] M. Behzadian, S. Khanmohammadi Otaghsara, M. Yazdani, and J. Ignatius, "A state-of the-art survey of TOPSIS applications", Expert Systems with Applications, Vol. 39, No. 17. Elsevier Ltd, pp. 13051-13069, 2012.

[16] S. Dzitac and I. Dzitac, "Fuzzy TOPSIS : A General View", Procedia Computer Science, Vol. 91, No. ITQM 2016, pp. 823-831, 2016.

[17] F. Kaleem, A. Mehbodniya, K. K. Yen, and F. Adachi, "Application of fuzzy TOPSIS for weighting the system attributes in overlay networks", In: Proc. of 14th Asia-Pacific Network Operations Management Symposium "Management Big Data IoT Era", APNOMS 2012 - Final Program, 2012.
[18] M. Mansouri and C. Leghris, "A Use of Fuzzy TOPSIS to Improve the Network Selection in Wireless Multiaccess Environments", Journal of Computer Networks Communications, Vol. 2020, pp. 1-12, 2020.

[19] K. Palczewski and W. Sałabun, "The fuzzy TOPSIS applications in the last decade", Procedia Computer Science, Vol. 159, pp. 2294-2303, 2019.

[20] E. N. Madi, J. M. Garibaldi, and C. Wagner, “An exploration of issues and limitations in current methods of topsis and fuzzy TOPSIS", In: Proc. of 2016 IEEE International Conf. on Fuzzy Systems, FUZZ-IEEE 2016, No. July, pp. 20982105, 2016. 